\title{
The role of matrix metalloproteinases and tissue inhibitors of matrix metalloproteinase in microcystic meningiomas
}

\author{
SUN HA PAEK ${ }^{1}$, DONG GYU KIM ${ }^{1}$, CHUL-KEE PARK ${ }^{1}$, JI HOON PHI ${ }^{1}$, YOUNG YIM KIM ${ }^{1}$, \\ SOO YOUNG IM ${ }^{1}$, JEONG EUN KIM ${ }^{1}$, SUNG-HYE PARK ${ }^{2}$ and HEE-WON JUNG ${ }^{1}$ \\ ${ }^{1}$ Department of Neurosurgery and Clinical Research Institute, ${ }^{2}$ Department of Pathology, Seoul National \\ University College of Medicine, Seoul National University Hospital, Seoul 110-744, Korea
}

Received November 22, 2005; Accepted March 23, 2006

\begin{abstract}
We studied the expression of matrix metalloproteinases (MMP) and tissue inhibitors of matrix metalloproteinase (TIMP) in microcystic meningiomas to investigate a possible underlying mechanism for the development of microcysts and of peritumoral edema, which are frequent characteristics of this rare subtype. Between October 1995 and June 2004, 10 of 19 patients who had histologically confirmed pure microcystic meningiomas were enrolled in the study. Six patients with meningothelial meningiomas, three with atypical meningiomas, and one with a transitional meningioma were included as a control group. Immunohistochemistry with paraffin blocks and real-time RT-PCR analysis for MMP-2, MMP-9, TIMP-1, TIMP-2 and vascular endothelial growth factor (VEGF) were performed using stored frozen tissues. Compared with the control group, MMP-9 was invariably and highly expressed in immunohistochemical staining of microcystic meningiomas. MMP-2, TIMP-1, TIMP-2 and VEGF were weakly expressed or not expressed in both microcystic and non-microcystic meningiomas. Realtime RT-PCR showed increased ratios of MMP-9 to TIMP-1 in microcystic meningiomas compared with the control group $(55.855 \pm 106.353$ vs. $1.858 \pm 2.575$, respectively; $\mathrm{p}=0.00)$. The expression of MMP-2 $(0.72 \pm 1.20$ vs. $2.54 \pm 3.01, \mathrm{p}=0.01)$ and TIMP-2 $(1.22 \pm 1.67$ vs. $1.61 \pm 1.82, \mathrm{p}=0.02)$ was higher in the control group. The results suggested that the increased ratio of MMP-9 to TIMP-1 might be associated with the formation of microcysts and peritumoral edema in microcystic meningioma.
\end{abstract}

\section{Introduction}

In 1956, Masson described a peculiar variant of meningioma of the humid or wet form, characterized by masses of meningeal

Correspondence to: Dr Dong Gyu Kim, Department of Neurosurgery, Seoul National University Hospital, 28 Yongon-dong, Chongno-gu, Seoul 110-744, Korea

E-mail: gknife@plaza.snu.ac.kr

Key words: microcystic meningioma, microcyst formation, peritumoral edema, MMP-9, TIMP-1, MMP-9/TIMP-1 ratio syncytium in the process of vacuolization with numerous lacunae or elongated slits and a very rich network of vessels (1). Subsequent reports of similar observations secured an acknowledgement of a new subtype of meningioma, which was designated 'microcystic meningioma' in the World Health Organization's classification system for brain tumors in 1993 $(2,3)$. Microcystic meningioma is rare, accounting for only $1.6 \%$ of intracranial meningiomas $(2,4)$. The characteristic features of microcystic meningiomas are numerous extracellular microcystic spaces containing fluid in histology and frequent association with peritumoral edema in radiology (5-9). Although microcystic meningiomas are included in the World Health Organization's Grade I group, as they have been believed to have a low risk of recurrence and aggressive growth (10), better understanding of the pathogenesis of their characteristic features may be of clinical value because microcyst formation and peritumoral edema are also observed in other variants and can affect therapeutic strategies.

Although several theories have been proposed to explain microcystic change and the frequent association of peritumoral edema with microcystic meningiomas, the underlying mechanism is still unknown. We focused on the matrix metalloproteinases (MMPs) and their related molecules, such as tissue inhibitors of matrix metalloproteinase (TIMPs), as well as vascular endothelial growth factor (VEGF), which is frequently discussed in relation to peritumoral edema. Because of their proteolytic activity, MMPs and TIMPs are extensively studied in the field of tumor invasion, edema formation and metastasis (11). Of the MMP family, which comprises at least 25 members, MMP-2 and MMP-9, also known as gelatinase A and gelatinase B respectively, are frequently mentioned in brain tumor biology with related molecules such as TIMP-1 and TIMP-2 (12). In this study, we present the results of immunohistochemical (IHC) and real-time RT-PCR analysis of microcystic meningiomas vs. non-microcystic meningiomas with emphasis on the expression of MMPs, TIMPs and VEGF and postulate a mechanism for microcyst formation and peritumoral edema.

\section{Materials and methods}

Between October 1995 and April 2004, 19 patients were histologically diagnosed as microcystic meningiomas. Frozen tissues of tumors from 10 patients had been stored at $-70^{\circ} \mathrm{C}$ 
Table I. Summary of radiological characteristics of the microcystic and non-microcystic meningiomas.

\begin{tabular}{lcllccl}
\hline Sex & $\begin{array}{c}\text { Age } \\
\text { (years) }\end{array}$ & Pathology & Tumor location & $\begin{array}{c}\text { Tumor volume } \\
\left(\mathrm{cm}^{3}\right)\end{array}$ & Edema index & Edema grade \\
\hline M & 52 & Microcystic & Convexity & 24.6 & 7.3 & IV \\
F & 66 & Microcystic & Convexity & 51.9 & 1.8 & III \\
F & 74 & Microcystic & Convexity & 27.4 & 3.6 & IV \\
M & 41 & Microcystic & Falx & 66.3 & 3.8 & IV \\
F & 71 & Microcystic & Convexity & 45.5 & 4.5 & IV \\
M & 64 & Microcystic & Convexity & 34.4 & 0.4 & II \\
F & 58 & Microcystic & Convexity & 13.2 & 4.4 & IV \\
M & 48 & Microcystic & Convexity & 46.6 & 4.3 & IV \\
F & 73 & Microcystic & Convexity & 30.5 & 0.3 & II \\
F & 55 & Microcystic & Convexity & 15.6 & 2.8 & IV \\
M & 42 & Meningothelial & Sphenoid wing & 88.4 & 0 & I \\
F & 54 & Meningothelial & Planum sphenoidale & 4.1 & 0 & I \\
F & 47 & Meningothelial & Sphenoid wing & 13.8 & 5.6 & IV \\
F & 73 & Meningothelial & Convexity & 30.2 & 0 & I \\
F & 51 & Meningothelial & Tuberculum sellae & 27.8 & 0 & I \\
F & 57 & Meningothelial & Convexity & 31.1 & 3.3 & IV \\
F & 57 & Transitional & Convexity & 8.6 & 0 & I \\
M & 55 & Atypical & Convexity & 24.7 & 1.5 & III \\
M & 66 & Atypical & Foramen magnum & 28.5 & 0 & I \\
F & 63 & Atypical & Falx & 21.2 & 4.3 & IV \\
\hline
\end{tabular}

and were available for our study. Ten randomly selected nonmicrocystic meningiomas (six meningiotheliomatous meningiomas, three atypical meningiomas, and one transitional meningioma) were included as a control group. The mean age of the microcystic meningioma patients was 60.2 years (range, 41-74 years) and that of the control group was 56.5 years (range, 42-73 years). Magnetic resonance imaging (MRI) was performed on all patients before surgery. The peritumoral brain edema was estimated from MRI as previously described (13). Briefly, the volume of edema $\left(\mathrm{V}_{\mathrm{E}}\right)$ surrounding meningioma was estimated by measuring the volume of the high signal intensity area around the tumor mass in T2-weighted images. Tumor volume $\left(\mathrm{V}_{\mathrm{T}}\right)$ was estimated using gadoliniumenhanced T1-weighted images. The edema index (EI) was defined as the ratio $\mathrm{V}_{\mathrm{E}} / \mathrm{V}_{\mathrm{T}}$, and graded as follows: absent or negligible (grade I) $(\mathrm{EI}<0.1)$; mild (grade II) $(0.1 \leq \mathrm{EI}<1.0)$; moderate (grade III) $(1.0 \leq \mathrm{EI}<2.0)$; severe (grade IV) $(\mathrm{EI} \geq 2.0)$. Craniotomy with gross total resection (GTR) of the tumor was performed in all cases. The tissue samples were snap frozen in liquid nitrogen immediately after operative removal. Immunohistochemistry and real-time RT-PCR were used to compare the expression of VEGF, MMPs and TIMPs between the microcystic and non-microcystic meningiomas.

For immunohistochemical analysis of VEGF, 5- $\mu \mathrm{m}$-thick cryostat sections were stained using the peroxidase-antiperoxidase method and detected using anti-VEGF antibodies (rabbit anti-human VEGF polyclonal antibody, Santa Cruz Biotech, Santa Cruz, CA). Antibody dilution was 1:10. For negative controls, only phosphate-buffered saline was applied without primary antibodies. IHC staining for MMP-2 (mouse anti-human MMP-2 monoclonal antibody, Chemicon International, Temecula, CA), MMP-9 (mouse anti-human MMP-9 monoclonal antibody, Chemicon International), TIMP-1 (mouse anti-human TIMP-1 monoclonal antibody, Chemicon International), and TIMP-2 (mouse anti-human TIMP-2 monoclonal antibody, Chemicon International) was performed in the same manner as VEGF staining. The IHC staining was evaluated by two observers independently in a blind fashion. The staining was assessed semi-quantitatively to determine both the percentage of labeled cells and the intensity of the IHC reaction. The degree of staining of meningioma specimens was graded as follows: i) negative or negligible, $<20 \%$ of cells labeled; ii) weak, $\geq 20 \%$ and $<50 \%$ of cells labeled; iii) moderate, $\geq 50 \%$ and $<75 \%$ of cells labeled; iv) strong, $\geq 75 \%$ of cells labeled.

For real-time RT-PCR, RNAs were extracted from tumor tissues using the guanidinium acid-phenol-chloroform method. The amount of RNA was estimated from the absorbance at $260 \mathrm{~nm}$ using a spectrophotometer. Reverse transcription of total-RNAs was performed using a Moloney murine leukemia virus reverse transcriptase $(1 \mu 1$, Promega, Madison, WI) with Oligo (dT) 15 primer $(500 \mu \mathrm{g} / \mathrm{ml}$, Promega) as a reverse primer, deoxynucleoside triphosphate mixture $(4 \mu 1)$, and recombinant RNasin ribonuclease inhibitor ( $1 \mu 1$, Promega) in a total volume of $20 \mu \mathrm{l}$ reaction buffer $(250 \mathrm{mM}$ Tris- $\mathrm{HCl}$, $\mathrm{pH} 8.3$ at $25^{\circ} \mathrm{C}, 375 \mathrm{mM} \mathrm{KCl}, 15 \mathrm{mM} \mathrm{MgCl}_{2}, 50 \mathrm{mM}$ DTT, 


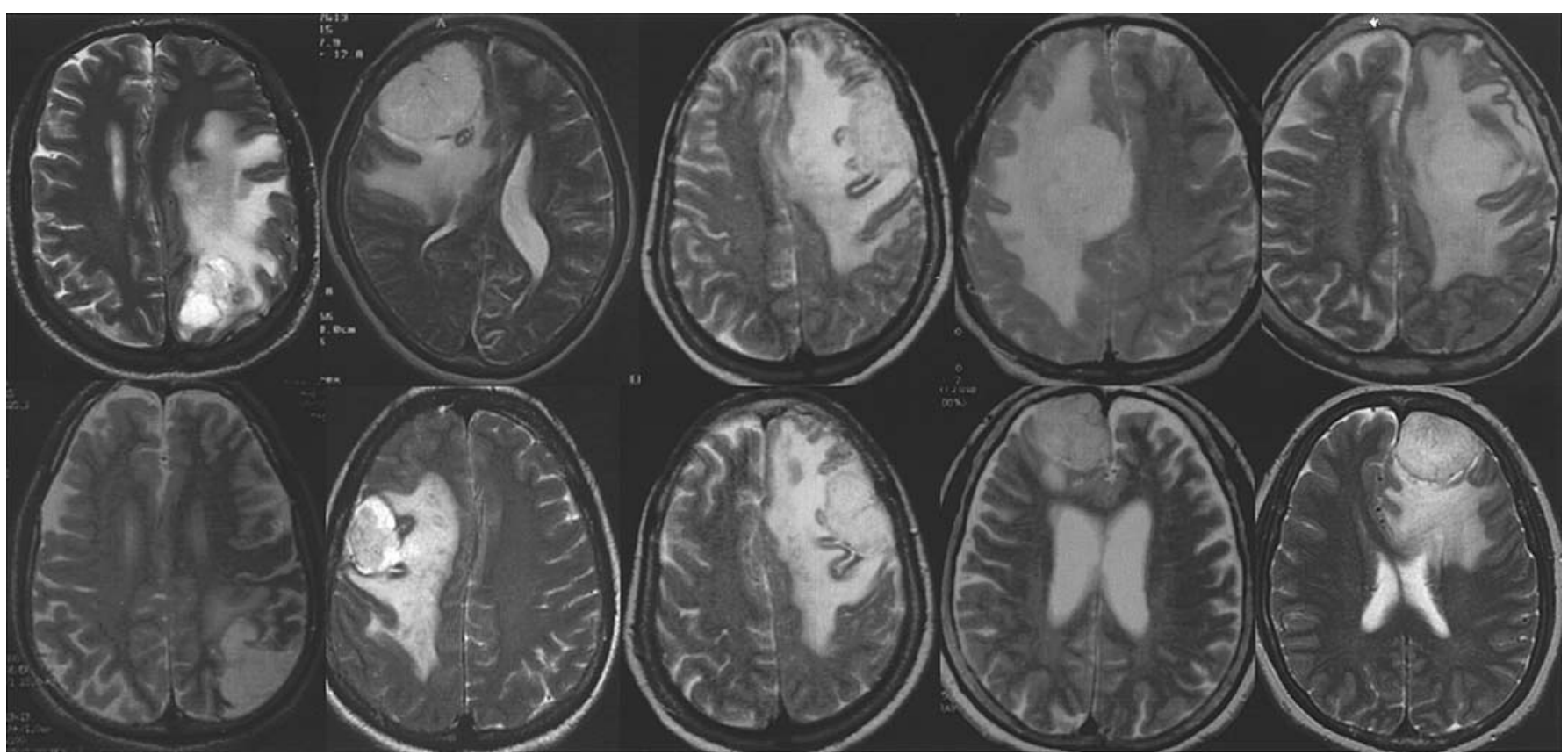

Figure 1. T2-weighted MRI of 10 patients with microcystic meningioma. The tumors are characteristically observed as a high-signal mass lesion in all cases. Note the predominant peritumoral edema.

Promega). The real-time RT-PCR was performed with $4 \mu \mathrm{l}$ of cDNA template in $20 \mu \mathrm{l}$ of PCR reaction product containing $2 \mu \mathrm{l}$ primers. Cycling conditions were $94^{\circ} \mathrm{C}$ for $10 \mathrm{~min}$ and then a 35- to 45 -cycle amplification phase at $94^{\circ} \mathrm{C}$ for $15 \mathrm{sec}$, $52^{\circ} \mathrm{C}$ for $15 \mathrm{sec}$ and $72^{\circ} \mathrm{C}$ for $20 \mathrm{sec}$. To evaluate the realtime RT-PCR approach, the GAPDH gene was used as a reference molecule for mRNA stability. For each sample, the amount of GAPDH mRNA was quantified relative to $1 \mu \mathrm{g}$ of the total-RNA. The oligonucleotide primers used for PCR were as follows: GAPDH (sense 5'-ACTTCAACAGCGACA CCCACTC-3' and antisense 5'-AGGCCCCTCCCCTCT TCA-3'); VEGF (sense 5'-CCCACTGAGGAGTCCAACA-3' and antisense 5'-TTTCTTGCGCTTTCGTTTT-3', 186 bp); MMP-2 (sense 5'-ATGACAGCTGCACCACTGA-3' and antisense 5'-ATTTGTTGCCCAGGAAAGT-3', 167 bp); MMP-9 (sense 5'-TTGACAGCGACAAGAAGTG-3' and antisense 5'-GCCATTCACGTCGTCCTTA-3', 179 bp); TIMP-1 (sense 5'-AATTCCGACCTCGTCATCA-3' and antisense 5'-TGCA GTTTTCCAGCAATGA-3', 230 bp); and TIMP-2 (sense 5'AAAGCGGTCAGTGAGAAGG-3' and antisense 5'-CTTCT TTCCTCCAACGTCC-3', 183 bp). Quantification of selected transcripts was performed using the Rotor-Gene 3000 system (Corbett Research, Sydney, Australia) and QuantiTect SYBRGreen PCR kits (Qiagen, Hilden, Germany). A fluorescence threshold cyclic turnover $(\mathrm{Ct})$ value was calculated for each sample. For each standard curve, the correlation coefficients ranged from 0.988 to 0.995 , indicating a high degree of confidence for measurement of the copy number of molecules in samples. The relative amount of mRNA was calculated from the difference in $\mathrm{Ct}$ values between different samples. All data are represented as means \pm standard errors.

All calculations were performed using a statistical analysis system (SAS version 9.0; SAS Institute Inc., Cary, NC). The comparison between groups was performed using the MannWhitney $\mathrm{U}$ test. We considered p-values of $<0.05$ as significant.

\section{Results}

Table I summarizes the radiological characteristics of all cases. MRI revealed that all microcystic meningiomas showed an intense high signal in T2 weighted images and peritumoral brain edema (Fig. 1). In the control group, peritumoral edema was observed in four of 10 patients. Histologically, all 10 cases of microcystic meningioma showed peculiar features that were distinguishable from those of the control group. They had a non-meningothelial appearance with vacuolated or microcystic spaces, which were intercellular or intracytoplasmic (Fig. 2). Frank xanthomatous cells were sometimes present. Whorls and psammoma bodies were very rare. Generally, blood vessels were abundant and frequently showed considerable vascular hyalinization. The tumor cells had large pleomorphic or hyperchromatic nuclei.

Immunohistochemical studies. The results of IHC studies are summarized in Table II. VEGF was not expressed in the tumor cells of the microcystic or control meningioma groups. MMP-9 was invariably and highly expressed in the IHC stainings of all microcystic meningiomas; weak expression of MMP-2 was observed (Fig. 3). However, TIMP-1 and TIMP-2 expression was negligible in all microcystic meningiomas. In contrast, MMP-9 was slightly expressed and TIMP-1 was rarely expressed in the control group. MMP-2 and TIMP-2 expression was negligible in all control group samples except one (Fig. 4).

Real-time RT-PCR. The relative values of mRNA of VEGF, MMP-2, MMP-9, TIMP-1 and TIMP-2 were quantified by real-time RT-PCR and adjusted by the difference from the $\mathrm{Ct}$ value of GAPDH of one patient in the control group. The results are summarized in Table III. The relative mean values for VEGF in the patients with microcystic meningiomas and 


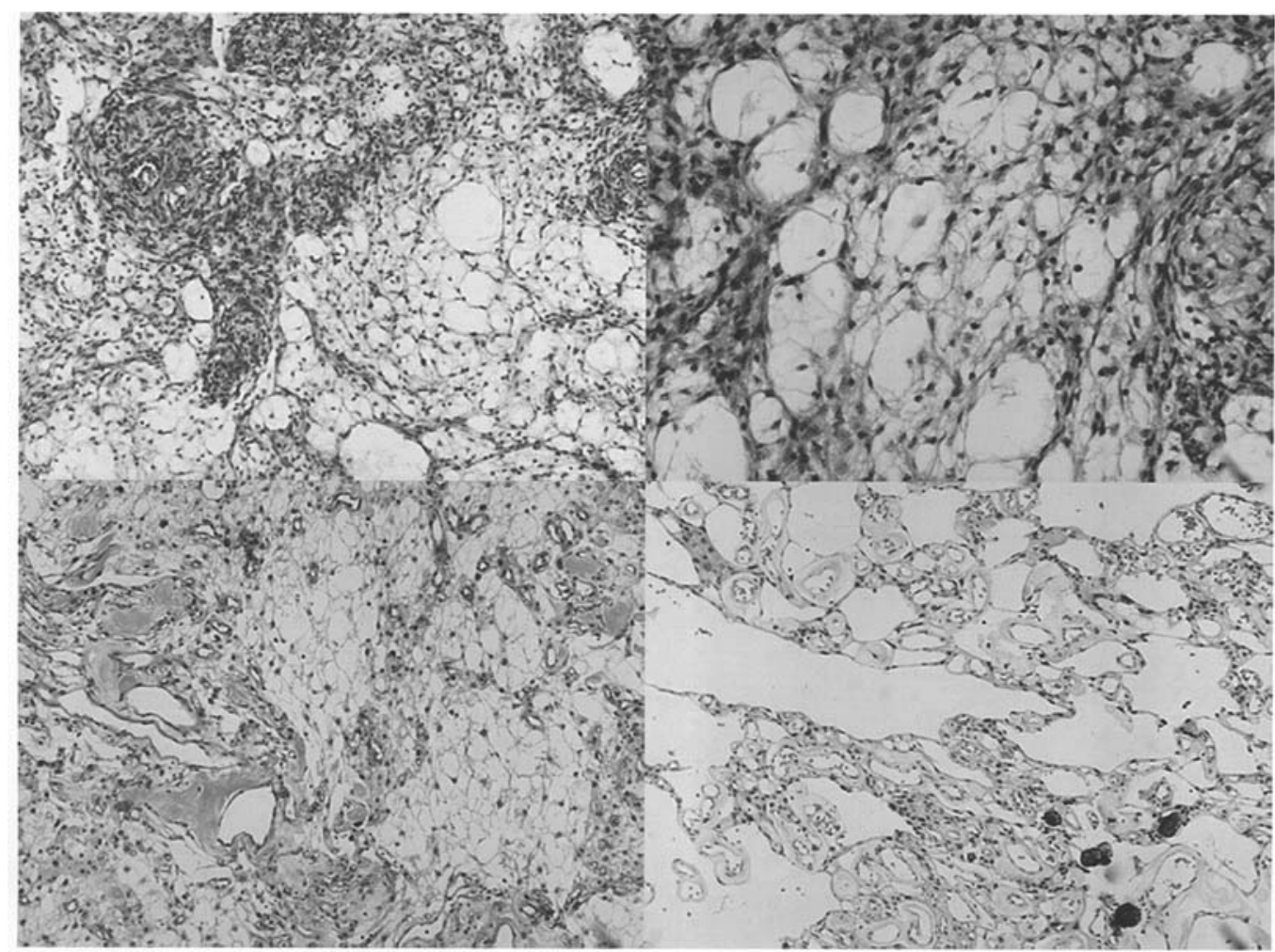

Figure 2. Histological features of microcystic meningiomas. Variable-sized cystic spaces and/or vacuolated cytoplasm with rich hyalinized blood vessels are seen (H\&E; original magnification: x100).

Table II. Results of immunohistochemical studies.

\begin{tabular}{|c|c|c|c|c|c|c|c|}
\hline Sex & Age (years) & Pathology & MMP-2 & TIMP-2 & MMP-9 & TIMP-1 & VEGF \\
\hline M & 52 & Microcystic & $1+$ & $1+$ & $3+$ & - & - \\
\hline $\mathrm{F}$ & 66 & Microcystic & $1+$ & - & $3+$ & - & - \\
\hline $\mathrm{F}$ & 74 & Microcystic & $1+$ & - & $3+$ & - & - \\
\hline M & 41 & Microcystic & $1+$ & - & $3+$ & - & - \\
\hline $\mathrm{F}$ & 71 & Microcystic & $1+$ & - & $3+$ & - & - \\
\hline M & 64 & Microcystic & $1+$ & - & $3+$ & - & - \\
\hline $\mathrm{F}$ & 58 & Microcystic & $1+$ & - & $3+$ & - & - \\
\hline M & 48 & Microcystic & $1+$ & - & $3+$ & - & - \\
\hline $\mathrm{F}$ & 73 & Microcystic & $1+$ & - & $3+$ & - & - \\
\hline $\mathrm{F}$ & 55 & Microcystic & $1+$ & - & $3+$ & - & - \\
\hline M & 42 & Meningothelial & - & - & $2+$ & - & - \\
\hline $\mathrm{F}$ & 54 & Meningothelial & - & - & $1+$ & - & - \\
\hline $\mathrm{F}$ & 47 & Meningothelial & - & - & $1+$ & - & - \\
\hline $\mathrm{F}$ & 73 & Meningothelial & - & - & $2+$ & - & - \\
\hline $\mathrm{F}$ & 51 & Meningothelial & - & - & $1+$ & - & - \\
\hline $\mathrm{F}$ & 57 & Meningothelial & - & - & $1+$ & - & - \\
\hline $\mathrm{F}$ & 57 & Transitional & - & - & $1+$ & - & - \\
\hline M & 55 & Atypical & - & - & $1+$ & - & - \\
\hline M & 66 & Atypical & $1+$ & $1+$ & $2+$ & - & - \\
\hline $\mathrm{F}$ & 63 & Atypical & - & - & $1+$ & - & - \\
\hline
\end{tabular}

The degree of reactivity is defined as follows: -, negative or negligible, $<20 \%$ of cells were labeled; $1+$, weak, $>20 \%$ and $<50 \%$ of cells were labeled; $2+$, moderate, $>50 \%$ and $<75 \%$ of cells were labeled; $3+$, strong, $>75 \%$ of cells were labeled. 


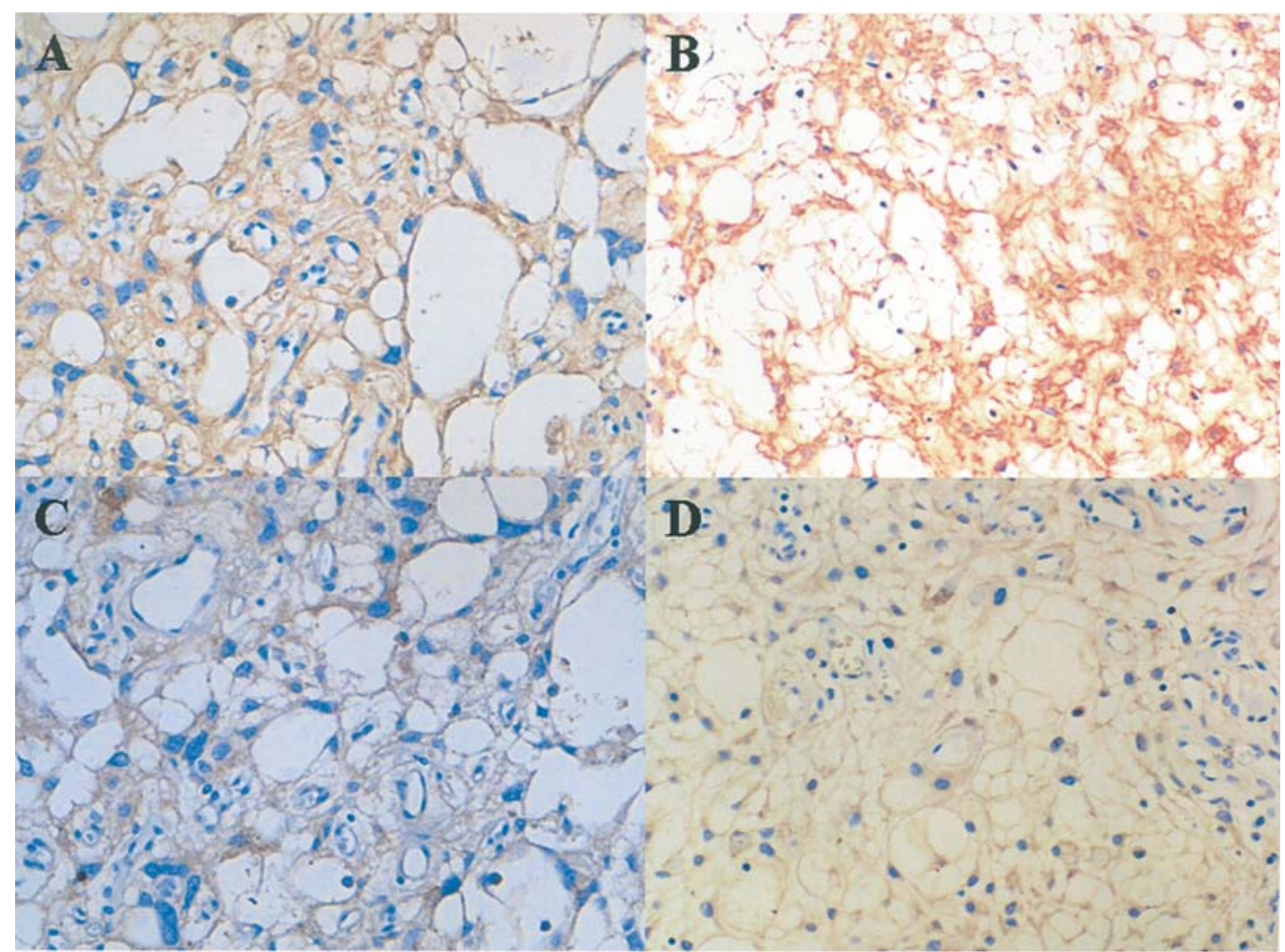

Figure 3. Immunohistochemical studies of microcystic meningioma. Weak staining for MMP-2 (A) is seen in cytoplasm of tumor cells, whereas strong expression of MMP-9 (B) is observed in the area of microcysts. Reactivity against TIMP-2 (C) and TIMP-1 (D) antibodies is negligible (original magnification: $\mathrm{x} 200)$.

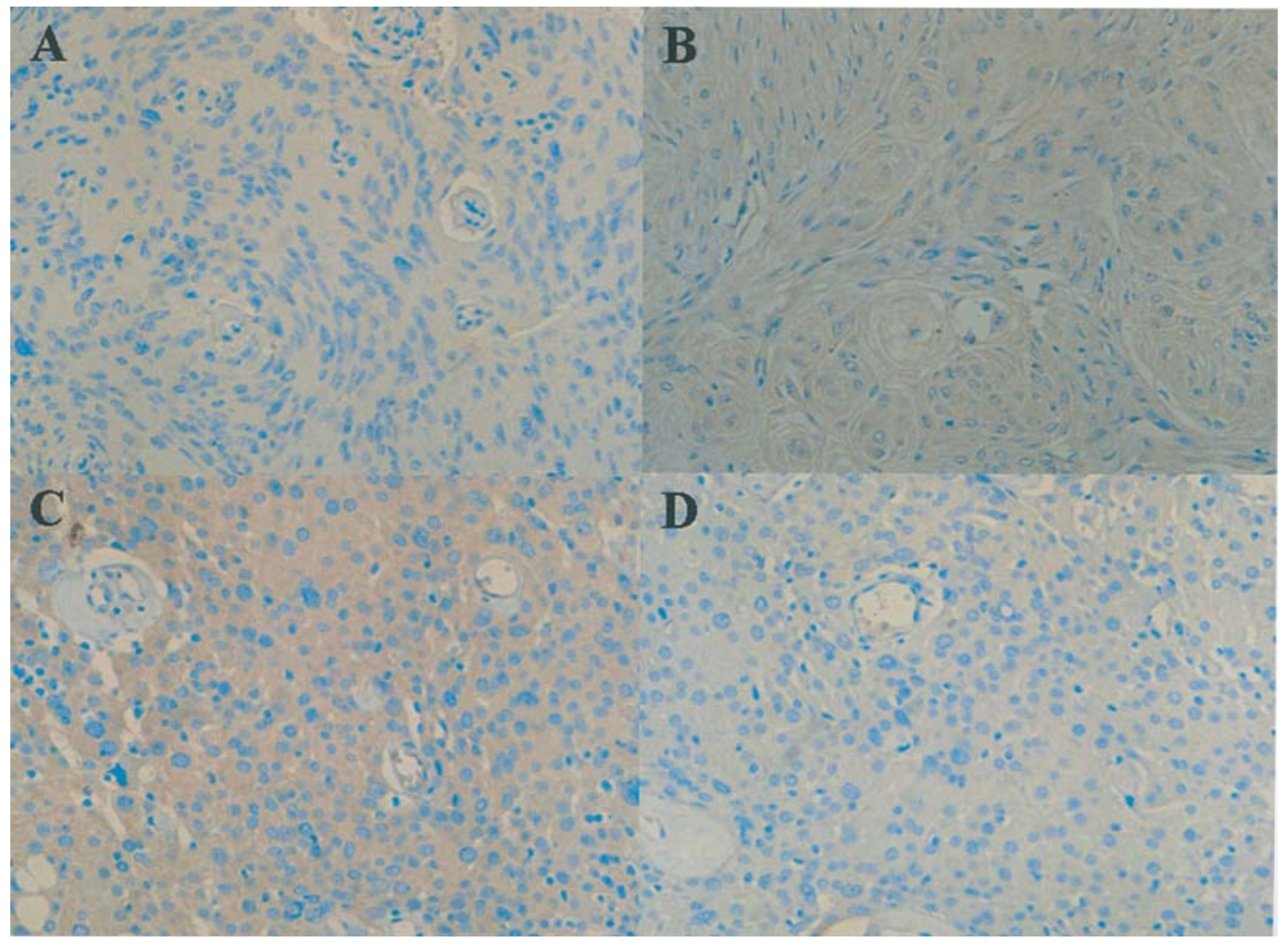

Figure 4. Immunohistochemical results for the control group. Staining for MMP-9 (B) shows moderate positive reaction. However, expression of MMP-2 (A), TIMP-2 (C) and TIMP-1 (D) is negligible (original magnification: x200).

those in the control group were $34.05 \pm 34.60$ and $38.20 \pm 53.72$, respectively, and did not differ significantly $(\mathrm{p}=0.88)$. The relative mean values for MMP-2 in patients with microcystic meningiomas were higher than those for the control group 
Table III. Results of real-time RT-PCR.

\begin{tabular}{|c|c|c|c|c|c|c|c|c|}
\hline Sex & Age (years) & Pathology & MMP-2 & TIMP-2 & MMP-9 & TIMP-1 & VEGF & MMP-9/MMP-1 \\
\hline M & 52 & Microcystic & 0.04 & 0.05 & 0.55 & 0.06 & 3.4 & 9.91 \\
\hline $\mathrm{F}$ & 66 & Microcystic & 0.62 & 0.60 & 4.53 & 0.10 & 65.8 & 44.6 \\
\hline $\mathrm{F}$ & 74 & Microcystic & 0.44 & 0.37 & 4.29 & 0.06 & 24.8 & 76.1 \\
\hline M & 41 & Microcystic & 0.43 & 0.80 & 0.17 & 0.03 & 51.6 & 6.46 \\
\hline $\mathrm{F}$ & 71 & Microcystic & 0.70 & 0.80 & 12.9 & 0.04 & 42.8 & 351.7 \\
\hline M & 64 & Microcystic & 4.08 & 1.71 & 7.78 & 1.12 & 108.3 & 6.96 \\
\hline $\mathrm{F}$ & 58 & Microcystic & 0.14 & 0.61 & 0.87 & 0.06 & 0.4 & 14.6 \\
\hline M & 48 & Microcystic & 0.39 & 0.25 & 0.71 & 0.11 & 13.0 & 6.63 \\
\hline $\mathrm{F}$ & 73 & Microcystic & 0.17 & 1.27 & 4.35 & 0.42 & 18.1 & 10.4 \\
\hline \multirow[t]{2}{*}{$\mathrm{F}$} & 55 & Microcystic & 0.16 & 5.78 & 34.1 & 1.09 & 2.3 & 31.12 \\
\hline & \multicolumn{2}{|c|}{ Mean } & 0.72 & 1.22 & 7.02 & 0.31 & 34.05 & 55.86 \\
\hline M & 42 & Meningothelial & 0.70 & 2.27 & 7.52 & 1.45 & 44.32 & 5.17 \\
\hline $\mathrm{F}$ & 54 & Meningothelial & 0.66 & 1.42 & 0.41 & 0.27 & 1.15 & 1.52 \\
\hline $\mathrm{F}$ & 47 & Meningothelial & 9.92 & 3.58 & 4.11 & 45.9 & 13.83 & 0.09 \\
\hline $\mathrm{F}$ & 73 & Meningothelial & 0.26 & 0.70 & 5.17 & 8.11 & 41.36 & 0.64 \\
\hline $\mathrm{F}$ & 51 & Meningothelial & 3.10 & 3.05 & 0.44 & 1.71 & 54.57 & 0.26 \\
\hline $\mathrm{F}$ & 57 & Meningothelial & 4.86 & 2.58 & 1.39 & 2.21 & 179.8 & 0.63 \\
\hline $\mathrm{F}$ & 57 & Transitional & 1 & 1 & 1 & 1 & 1 & 1 \\
\hline M & 55 & Atypical & 0.61 & 6.11 & 22.5 & 2.85 & 36.76 & 7.89 \\
\hline M & 66 & Atypical & 0.96 & 0.63 & 1.73 & 1.96 & 3.34 & 0.88 \\
\hline $\mathrm{F}$ & 63 & Atypical & 3.29 & 4.76 & 0.66 & 1.31 & 5.86 & 0.5 \\
\hline \multicolumn{3}{|c|}{ Mean } & 2.54 & 1.61 & 4.50 & 6.68 & 38.20 & 1.86 \\
\hline
\end{tabular}

The relative quantified values of m-RNA for VEGF, MMP-2, MMP-9, TIMP-1 and TIMP-2 adjusted by the difference from the cyclic turnover $(\mathrm{Ct})$ value of GAPDH of one patient in the control group.

$(0.72 \pm 1.20$ vs. $2.54 \pm 3.01$, respectively; $p=0.01)$. TIMP-2 relative mean values were also higher in microcystic meningioma patients than in the control group $(1.22 \pm 1.67 \mathrm{vs}$. $1.61 \pm 1.82$, respectively; $\mathrm{p}=0.02)$. Although the relative mean value for MMP-9 in the patients with microcystic meningiomas (7.02 \pm 10.29$)$ was numerically higher than that of the control group $(4.49 \pm 6.75)$, the difference was not statistically significant $(\mathrm{p}=0.60)$. However, because relative mean values for TIMP-1 were significantly lower in patients with microcystic meningiomas compared with the control group $(0.31 \pm 0.44$ vs. $6.68 \pm 13.95$, respectively; $p=0.00)$, the mean ratio of MMP-9/TIMP-1 was significantly different between the groups $(55.86 \pm 106.35$ vs. $1.86 \pm 2.58$, respectively; $\mathrm{p}=0.00)$.

\section{Discussion}

The pathogenesis of the characteristic extracellular microcyst formation in microcystic meningiomas is obscure. Several hypotheses have been proposed to explain microcyst formation in microcystic meningiomas. Masson proposed tumoral imbibition by cerebrospinal fluid (CSF) transudation and stressed the similarity between this type of meningioma and normal leptomeninges (1). Michaud and Gagne also postulated that transudation is a possible mechanism because these tumors are richly vascularized and the vascular endothelium is partly fenestrated (14). However, their suggestions seem very unlikely, as these tumors had thick fibrous capsules and were clearly demarcated from the surrounding subarachnoid spaces (15). Other studies indicated tumor cell degeneration, increased secretory activity of the tumor cells, or hyperpermeability of the vessels as the basis of cyst formation in microcystic meningiomas (16-18). However, most reports lack well-grounded evidence. It has also been stated that microvascular hyperpermeability precedes or accompanies angiogenesis (19). Christov et al speculated that the vessel permeabilization and probably the angiogenetic effects of overexpression of vascular permeability factor (VPF) and VEGF might be responsible for the histological appearance of microcystic meningioma (20). However, they reported that meningiomas with partial microcystic patterns had no VPF/ VEGF vessel labeling (20). It has been stated that microcystic meningiomas could derive from trabecular arachnoid cells and recapitulate the mesh-like structure of the subarachnoid space (21). Recently, Yamazaki et al reported that the complex interdigitation of tumor cell processes was not detected in their 
immunohistochemical and electron microscopic examinations of four microcystic meningiomas (22). This is an interesting point as the complex interdigitation of tumor cell processes without intervening basal lamina material is the most consistent and distinctive ultrastructural feature of other subtypes of meningioma, although fibroblastic variants tend to have a more parallel alignment (23). Therefore, gap-junctional features observed in microcystic meningioma could be interpreted as part of the abortive tumor cell differentiation, mimicking the physiological function of arachnoidal cells that regulate or absorb the cerebrospinal CSF between blood vessels and brain parenchyma (22). Proteolytic activity mediated by MMPs and related molecules may be attributed to loss of complex interdigitation of the tumor cell process and accumulation of abortive matrix destruction product in the intercellular space, which eventually forms microcysts. In our study, the strong expression of MMP-9 and the MMP-9/TIMP-1 imbalance in patients with microcystic meningiomas constitutes plausible evidence for such a condition. We found no evidence of VEGF involvement in the development of microcysts in microcystic meningioma.

MMPs are an ever-expanding family of endopeptidases with proteolytic activity towards one or more components of the extracellular matrix $(24,25)$. These enzymes are grouped into the following categories on the basis of their substrate specificity: i) interstitial collagenases (MMP-1, MMP-8 and MMP-13); ii) type IV collagenases (MMP-2 and MMP-9); and iii) stromelysins (MMP-3, MMP-10, MMP-11), which contain a unique transmembrane domain in their $\mathrm{COOH}$ terminal that localizes these MMPs on the cell surface (26). Among them, MMP-2 and MMP-9 are expressed as pro-forms, activated by cleavage of their amino terminal, and are consequently involved in proteolysis of the basement membrane and extracellular matrix $(27,28)$. MMP activity is regulated by gene expression, proenzyme activation, and inhibition of active enzymes by specific TIMPs $(29,30)$. Specifically, TIMP-1 inhibits MMP-9 activity whereas TIMP-2 regulates MMP-2 activity (11). TIMPs are also involved in regulation of cell proliferation, apoptosis and angiogenesis (31). TIMPs bind active or latent forms of MMPs in a molecular 1:1 ratio. The balance of relative concentrations of active MMPs and their inhibitors determines the net proteolytic activity (32). Substantial work over the past decade has shown that MMPs play a pivotal role in the process of malignant progression and that inhibition of MMP-9 activity results in reduction of tumor invasion and metastasis in animal studies $(33,34)$. Rooprai et al reported the expression of MMP-2 and MMP-9 in short-term cultures of 18 human meningiomas, including seven meningiothelial, six transitional, two fibroblastic and three atypical meningiomas (35). They observed that the meningothelial subtype had the weakest expression and the transitional subtype had an intermediate expression, whereas the fibroblastic subtype had the strongest expression of both MMP-2 and MMP-9 (35). Nordqvist et al studied the expression of MMP-2 and MMP-9 in 16 meningiomas with different degrees of brain invasion and edema using in situ hybridization (36). They found that meningiomas express both MMP-2 and MMP-9, but tumor invasiveness correlated with the extent of MMP-9 expression (36). Halaka et al reported that invasive meningiomas produced significantly lower levels of TIMP-1 than non-invasive meningiomas (37). Mizoue et al mentioned that the balance between MMP-9 and TIMP-1 secretion influenced the infiltrative capacity of meningiomas (38). It is now generally accepted that the net balance of MMP-9/TIMP-1 is more important for angiogenesis and tumor invasion in brain tumors than MMP expression per se (39).

MMPs have also been advocated as being one of the key molecules in peritumoral edema. Rosenberg et al demonstrated that intracerebral injection of MMPs resulted in leakage of microvessels in an animal study (40). MMP-9 expression was correlated with disruption of the blood-brain barrier in a clinical study (41). Christov et al suggested that increased immunohistochemical expression of VPF and VEGF was common in meningiomas and was frequently associated with peritumoral edema meningiomas (20). We have previously reported that levels of MMP-9 were significantly elevated in a moderateto-severe edema group whereas levels of MMP-2 were elevated in a minimal-to-mild edema group of 20 meningiomas with various degree of peritumoral edema; we suggested that there are close relationships between peritumoral edema and MMP-2, MMP-9 and the ratio of MMP-9/TIMP-1, but not with VEGF (13). We reported that there was an increased activity of MMP-9 and an imbalance of MMP-9/TIMP-1 ratio in the moderate-to-severe peritumoral edema group (13). In the present study, identical results were achieved in the microcystic meningioma group, which consisted of dominant peritumoral edema. However, there were some discrepancies in individual cases: microcystic meningioma with relatively less severe peritumoral edema was associated with higher MMP-9/ TIMP-1 ratios than non-microcystic meningioma with severe peritumoral edema. This implies that, although an MMP-9/ TIMP-1 imbalance contributes to the development of peritumoral edema, other unknown mechanisms may also exist.

This is the first study in which the concomitant expression of MMPs and TIMPs has been evaluated to address the mechanisms underlying microcyst formation and peritumoral edema in microcystic meningiomas. However, there are some limitations to the interpretation of the data. One of the problems of the real-time RT-PCR system is that little is known about the total-RNA content per cell for various tissues or how this might vary between individuals or between normal and tumor tissue. Therefore, there is a risk of making an error in estimating the quantity of RNA in the sample. Another problem is that it has been documented that mRNA levels of GAPDH are not constant, suggesting that GAPDH is not always suitable as a reference despite its wide use. A limitation of SYBR-Green is that it binds equally well to non-specific products, such as primer dimmers, and the desired PCR product. This interferes with the quantification of the desired PCR product.

In conclusion, an MMP-9/TIMP-1 imbalance might be associated with the formation of microcysts and the frequent occurrence of peritumoral edema in microcystic meningioma. However, the pathogenesis of microcystic meningioma remains to be fully elucidated, particularly the development of peritumoral edema, which may be complex.

\section{Acknowledgements}

This study was partially supported by a grant from Seoul National University Hospital Clinical Research Institute. 


\section{References}

1. Masson P: Meningiomes. Maloine, Paris, pp977-988, 1956.

2. Kleihues P, Burger BP and Scheithauer BW: The new WHO classification of brain tumours. Brain Pathol 3: 255-268, 1993.

3. Scheithauer BW: Tumors of the meninges: proposed modifications of the World Health Organization classification. Acta Neuropathol 80: 343-354, 1990

4. Kuchna I, Matyja E, Wierzba-Bobrowicz T and Mazurowski W: Microcystic meningioma - a rarely occurring morphological variant of meningioma. Folia Neuropathol 32: 259-263, 1994.

5. Cho JH, Yang KH, Zhang HY and Kie JH: Microcystic meningioma - unusual variant of meningiomas. J Korean Neurosurg Soc 34: 382-385, 2003.

6. Paek SH, Kim SH, Chang KH, et al: Microcystic meningiomas: radiological characteristics of 16 cases. Acta Neurochir 147: 965-972, 2005.

7. Paik SS, Jang SJ, Park YW, Hong EK, Park MH and Lee JD: Microcystic meningioma. A case report. J Korean Med Sci 11: 540-543, 1996

8. Bromley PJ, Grymaloski MR and Zetler PJ: CT appearance of microcystic meningioma. J Comput Assist Tomogr 20: 570-572, 1996.

9. Nishio S, Takeshita I and Fukui M: Microcystic meningioma: tumors of arachnoid cap vs. trabecular cells. Clin Neuropathol 13: 197-203, 1994

10. Louis DN, Scheithauer BW, Budka H, von Deimling A and Kepes JJ: Meningiomas. IARC Press, Lyon, 2000.

11. Brinckerhoff CE and Matrisian LM: Matrix metalloproteinases: a tail of a frog that became a prince. Nat Rev Mol Cell Biol 3: 207-214, 2002.

12. Siddique K, Yanamandra N, Gujrati M, Dinh D, Rao JS and Olivero W: Expression of matrix metalloproteinases, their inhibitors, and urokinase plasminogen activator in human meningiomas. Int J Oncol 22: 289-294, 2003.

13. Paek SH, Kim CY, Kim YY, et al: Correlation of clinical and biological parameters with peritumoral edema in meningioma. J Neurooncol 60: 235-245, 2002.

14. Michaud J and Gagne F: Microcystic meningioma. Clinicopathologic report of eight cases. Arch Pathol Lab Med 107: 75-80, 1983.

15. Orita T, Kamiryo T, Nishizaki T, Kurokawa Y, Akimura T and Aoki H: Meningioma with extensive vacuolization - a contribution to the pathogenesis of intratumoral cyst formation. Clin Neuropathol 8: 301-306, 1989.

16. Choux R, Hassoun J and Gambarelli D: Ultrastructural study of a Masson's 'humid meningioma'. Bull Cancer 62: 125-136, 1975.

17. Nishio S, Takeshita I, Morioka T and Fukui M: Microcystic meningioma: clinicopathological features of 6 cases. Neurol Res 16: 251-256, 1994

18. Ng HK, Poon WS, South JR and Lee JC: Tumours of the central nervous system in Chinese in Hong Kong: a histological review. Aust N Z J Surg 58: 573-578, 1988.

19. Dvorak HF, Brown LF, Detmar M and Dvorak AM: Vascular permeability factor/vascular endothelial growth factor, microvascular hyperpermeability and angiogenesis. Am J Pathol 146: 1029-1039, 1995.

20. Christov C, Lechapt-Zalcman E, Adle-Biassette H, Nachev S and Gherardi RK: Vascular permeability factor/vascular endothelial growth factor (VPF/VEGF) and its receptor flt- 1 in microcystic meningiomas. Acta Neuropathol 98: 414-420, 1999.

21. Ito H, Kawano N, Yada K and Kameya T: Meningiomas differentiating to arachnoid trabecular cells: a proposal for histological subtype 'arachnoid trabecular cell meningioma'. Acta Neuropathol 82: 327-330, 1991.

22. Yamazaki K and Eyden B: An ultrastructural and immunohistochemical study of microcystic meningioma with emphasis on matrix proteins and connexin 26 type gap junctions. Ultrastruct Pathol 28: 247-253, 2004.
23. Arishima H, Sato $\mathrm{K}$ and Kubota T: Immunohistochemical and ultrastructural study of gap junction proteins connexin 26 and 43 in human arachnoid villi and meningeal tumors. J Neuropathol Exp Neurol 61: 1048-1055, 2002.

24. Visse R and Negase H: Matrix metalloproteinases and tissue inhibitors of metalloproteinases: structure, function and biochemistry. Circ Res 92: 827-839, 2003.

25. Lesauskaite V, Tanganelli P, Sassi C, et al: Smooth muscle cells of the media in the dilatative pathology of ascending thoracic aorta: morphology, immunoreactivity for osteopontin, matrix metalloproteinases and their inhibitors. Hum Pathol 32: 1003-1011, 2001.

26. Mignatti P and Rifkin DB: Plasminogen activators and matrix metalloproteinases in angiogenesis. Enzyme Protein 49: 117-137, 1996.

27. Ray JM and Stetler-Stevenson WG: The role of matrix metalloproteinases and their inhibitors in tumour invasion, metastasis, and angiogenesis. Eur Respir J 7: 2062-2072, 1994.

28. Apodaca G, Rutka JT, Bouhana K, et al: Expression of metalloproteinases and metalloproteinase inhibitors by fetal astrocytes and glioma cells. Cancer Res 50: 2322-2329, 1990.

29. Fini ME, Cook JR, Mohan R and Brinckehoff C: Regulation of Matrix Metalloproteinases Gene Expression. Academic Press, San Diego, 1998.

30. Gomez DE, Alonso DF, Yoshiji $\mathrm{H}$ and Thorgeirsson UP: Tissue inhibitors of metalloproteinases: structure, regulation and biological functions. Eur J Cell Biol 74: 111-122, 1997.

31. Fernandez HA, Kallenbach K, Seghezzi G, et al: Inhibition of endothelial cell migration by gene transfer of tissue inhibitor of metalloproteinases-1. J Surg Res 82: 156-162, 1999.

32. Kadoglou NP and Liapis CD: Matrix metalloproteinases: contribution to pathogenesis, diagnosis, surveillance and treatment of abdominal aortic aneurysms. Curr Med Res Tech 20: 419-432, 2004.

33. Davies B, Brown PD, East N, Crimmin MJ and Balkwill FR: A synthetic matrix metalloproteinase inhibitor decreases tumor burden and prolongs survival of mice bearing human glioblastoma cells. Cancer Res 53: 2087-2091, 1993.

34. Lozonschi L, Sunamura M, Kobari M, Egawa S, Ding L and Mastuno S: Controlling tumor angiogenesis and metastasis of C26 murine colon adenocarcinoma by a new matrix metalloproteinase inhibitor, KB-R7785, in two tumor models. Cancer Res 59: 1252-1258, 1999.

35. Rooprai HK, van Meter TE, Robinson SD, King A, Rucklidge GJ and Pilkington GJ: Expression of MMP-2 and -9 in short-term cultures of meningioma: influence of histological subtype. Int J Mol Med 12: 977-981, 2003.

36. Nordqvist AC, Smurawa $\mathrm{H}$ and Mathiesen T: Expression of matrix metalloproteinases 2 and 9 in meningiomas associated with different degrees of brain invasiveness and edema. J Neurosurg 95: 839-844, 2001.

37. Halaka AN, Bunning RA, Bird CC, Gibson M and Reynolds JJ: Production of collagenase and inhibitor (TIMP) by intracranial tumours and dura in vitro. J Neurosurg 59: 461-466, 1983.

38. Mizoue T, Kawamoto H, Arita K, Tominaga A and Kurisu K: Secretion of matrix metalloproteinase- 9 and tissue inhibitor of metalloproteinase- 1 by meningiomas detected by cell immunoblot analysis. Acta Neurochir 141: 481-486, 1999.

39. Kachra Z, Beaulieu E, Delbecchi L, et al: Expression of matrix metalloproteinases and their inhibitors in human brain tumors. Clin Exp Metastasis 17: 555-566, 1999.

40. Rosenberg GA, Kornfeld M, Estrada E, Kelley RO, Liotta LA and Stetler-Stevenson WG: TIMP-2 reduces proteolytic opening of blood-brain barrier by type IV collagenase. Brain Res 576: 203-207, 1992.

41. Lee MA, Palace J, Stabler G, Ford J, Gearing A and Miller K: Serum gelatinase B, TIMP-1 and TIMP-2 levels in multiple sclerosis. A longitudinal clinical and MRI study. Brain 122: 191-197, 1999. 